

www.turkishstudies.net/appliedsciences
eISSN: 2667-5633

Research Article / Araştırma Makalesi



INTERNATIONAL

BALKAN

UNIVERSITY

Sponsored by IBU

\title{
Üstün Yetenekeli Öğrencilerin Oyun Tasarımı ve Kodlama Eğitimi Programları Hakkında Görüşleri
}

\author{
Gifted Students' Opinions about Game Design and Coding Training Programs
}

\author{
Ebru Toklu* - Aysan Şentürk ${ }^{* *}$
}

\begin{abstract}
It is considered that for the gifted students, the needs and needs of the age should be taken into consideration while providing the trainings that are needed in the age. Today, education and training programs are based on 21st century skills and education and training are shaped in this respect. Analytical thinking, creativity and problem solving skills are some of the characteristics that are intended to be gained in education. Game design and coding training courses are of great importance in achieving the targeted features and it is thought that gifted students are easier to achieve these goals. But what are the opinions of gifted students about game design and programs used in coding education? In this study, it was tried to learn the opinions of the gifted students about game design and coding education classes. The study was carried out in Bursa province with 20 students who 10 years old. Qualitative research method was used in the study. The data were obtained by semi-structured interviews with each of the students. The data were analyzed by content analysis and the inductive method was used. For the reliability of the cohen, the kappa number was found to be 0,87 by two different researchers and the data was triangulated for the reliability of the themes. As a result of the study, it was determined that the students preferred three-dimensional programs, they were very satisfied with the Turkish language support and they wanted to add objects and backgrounds from the program. It has been determined that the coding section should be supported with visual objects, and that it is the expectations of the students to make updates more.
\end{abstract}

Structured Abstract: Gifted individual; who are defined as superior in certain tests, who perform in one or more of the different disciplines such as art, science and technology, who perform well above their peers' performance and who are task conscious and highly motivated but who need special education in addition to formal education due to their superior and special abilities (Moore, 1992). Renzulli, 1999; Sak, 2011). Considering these impulses;

\footnotetext{
* Uzman, Bursa Uludağ Üniversitesi, Eğitim Bilimleri Enstitüsü, Bilgisayar ve Öğretim Teknolojileri Eğitimi Bölümü Master's Degree, Bursa Uludă̆ University, Institute of Education Sciences, Department of Computer and Education Technologies Education 
Turkey also signed by the United Nations, whatever the ability of every child born by the Children's Rights Convention to receive training to enhance their capacity and has the right to self-improvement (Levent, 2014).

When the 21 st century human skills are considered, it is expected that the technology enters the human life and individuals will have information about the products and services that are the return of technology. Game design and coding trainings can be included in the courses both to follow technological developments and educational literature and to develop students' skills such as problem solving and different thinking. It is seen that most countries are aware of the contributions of game design and coding trainings and have been included in education and training curricula.

Developed and developing countries that do not want to fall behind the education agenda include game design and coding trainings in their training programs. In gifted education is also one of the core courses in game design and coding. In addition to Science and Arts Centers (BILSEM), there are special education centers for gifted students, children's universities, weekend and summer schools for game design and coding training programs for gifted individuals (Levent, 2011). When the studies are examined, it is seen that gifted and talented students exhibit a high level of positive attitude towards computer and computer related topics and these positive attitudes as well as advanced knowledge and skills (Keskin, 2006). For the gifted students, especially for Science and Arts Centers (BILLSEM), rich content programs are offered based on the enrichment of educational coding training curricula.

Game design and coding education curriculum programs are the two most commonly used programs; Scratch and Code Game Lab programs. Visual programming and block based programming logic are considered suitable for younger students (Coy, 2013; Scratch, 2018). Gifted students who are very keen on technology are trying to find opinions about the two most used programs for game design and coding education. Within this general purpose- the sub-objectives of the research are:

Gifted students;

- What are their views on the Scratch program?

- What are your opinions about the Kodu Game Lab program?

In order to determine the views of gifted students about game design and coding training programs Scratch and Kodu Game Lab, case study design was used from qualitative research designs and the research was carried out with semi-structured interview technique. Research participants; Turkey, located in Bursa province is 20 students were reporting that 10 year old gifted with certain tests. On the weekend training course, students took 20 weeks of Scratch and Kodu Game Lab program for one hour per week.

The collected data were divided into meaningful sections and coded by analyzing the data by two different researchers based on induction analysis. Cohen Kappa coefficient was used to reveal the reliability of the codes and research. The matrix table of the two researchers was calculated and $87 \%$ was found to be very good agreement between the data (Landis \& Koch, 1977).

When the data obtained from two interview questions were analyzed and divided into themes, 4 themes were formed. The gifted students have positive opinions in the Scratch program, negative views in the Scratch program, positive views in the Kodu Game Lab program, and negative views in the Kodu Game Lab program.

The aim of this research is to learn the views of gifted students about the two most preferred programs in game design and coding education courses. It was determined that students liked the multiplicity of objects, color quality and coding part related to scratch program. It is seen that the image quality and the digital dimension of the program diminishes the positive thoughts about the program because it is seen that they expect the 3D image quality which is frequently used in digital games in the games they designed themselves. It is thought that how much students can participate in the game they designed will contribute to the development of problem solving skills (Jonassen, 2000).

Another preference of the students is the inclusion of external objects in the game designs. While this is possible with Scratch, Kodu Game lab program does not have such a feature.

Block based coding is used in the coding section of Scracth and Kodu Game Lab programs. However, it is seen that the game lab aims to help the students do coding not only with literacy but also with visual aid by adding the picture feature to the coding blocks as an additional feature. 
It indicates that there are few academic studies on game design and coding education which is the research field. It is determined that there are very few academic studies about gifted game design and coding education. By increasing the number of participants for future studies, studies can be expanded by adding more game design and coding training programs. Research methods are not limited to qualitative but quantitative and mixed methods can be used.

One of the limitations of the study is that the study is based only on qualitative data and is limited to content analysis. Considering the diversity of game design and coding programs, working with two programs is a limitation and more programs can be evaluated by taking into the educational content.

Keywords: gifted students, game desing anda coding, scratch, kodu game lab.

Öz: Üstün yetenekli öğrenciler için çağın gereksinimi olan eğitimler verilirken onların ilgi ve ihtiyaçlarının göz önünde bulunması gerektiği düşünülmektedir. Günümüzde eğitim ve öğretim programları oluşturulurken 21. Yüzyıl becerileri temel alınmakta ve eğitim ve öğretim bu açıdan şekillenmektedir. Analitik düşünme, yaratıcılık ve problem çözme becerileri eğitim içerisinde kazandırılması hedeflenen özelliklerden bazılarıdır. Hedeflenen özelliklere ulaşılmasında oyun tasarımı ve kodlama eğitimi dersleri büyük önem taşımakta ve üstün yetenekli öğrencilerin bu hedeflere ulaşması daha kolay olduğu düşünülmektedir. Peki üstün yetenekli öğrencilerin oyun tasarımı ve kodlama eğitiminde kullanılan programlar hakkında görüşleri nelerdir? Yapılan çalışma ile üstün yetenekli öğrencilerin oyun tasarımı ve kodlama eğitimi derslerinde en sık kullanılan scratch ve kodu game lab programları hakkında görüşleri öğrenilmeye çalışılmıştır. Yapılan çalışmaya Bursa ilinde,10 yaşında üstün yetenekliliği raporla belirlenmiş 20 öğrenci ile çalışılmıştır. Çalışmada nitel araştırma yöntemi kullanılmıştır. Veriler, öğrencilerin her biri ile yarı yapılandırılmış görüşme yapılarak elde edilmiştir. Elde edilen veriler içerik analizi ile analiz edilirken tümevarımsal yöntem kullanılmıștırtır. İki farklı araştırmacı tarafından kodlamalar yapılarak güvenirliği için cohen'in kappa sayısı 0,87 bulunmuştur ve temaların güvenirliği için veri üçgenlemesi yapılmış̦tır. Çalışma sonucunda öğrencilerin üç boyutlu programları tercih ettikleri, türkçe dil desteğinden çok memnun oldukları ve program içerisine dışarıdan nesne ve arkaplan eklemeyi istedikleri belirlenmiştir. Kodlama bölümünün görsel nesnelerle desteklenilmesi gerektiğini ve güncellemelerin daha fazla yapılmasının öğrencilerin beklentileri olduğu belirlenmiştir.

Anahtar Kelimeler: üstün yetenekli öğrenciler, oyun tasarımı ve kodlama, scratch, kodu game lab

\section{Giriş}

Üstün yeteneklilik ile ilgili alanyazında birçok tanım ve kuram bulunmaktadır. Bu tanımlar ve kuramların kabul görme durumları, coğrafyaya, ülkenin gelişmişlik seviyesine, toplumun önceliği olan değerlerine göre farkl1lık gösterebilmektedir (Levent, 2014). Genel kabul edilen üstün yetenekli birey tanımı; belirli testler ile üstünlüğü tanımlanmış, sanat, bilim, teknoloji gibi farklı bilim dallarından birinde veya birkaçında akranlarından beklenen performansın üstünde performans gösteren ve görev bilincine ve yüksek motivasyona sahip ancak üstün ve özel yetenekleri sebebiyle örgün eğitime ek olarak özel eğitime ihtiyaç duyan birey şeklindedir (Moore, 1992; Renzulli, 1999; Sak, 2011). Üstün yetenekli bireyler ile ilgili çalışmaların tarihine bakıldığında 2000 yıldan öncesi Çin ve Yuan imparatorluklarına kadar dayanmaktadır. Bu çalışmalar bilimsel nitelikte olmayıp, bireylerin zihinsel ve fiziksel farklılıklarıyla alakalıdır. İlk bilimsel çalışmalar ise 19. Yüzyılda İngiliz bilim insanı Galton tarafından yapılmıştır (Türk Zeka Vakfı, 2013). Galton duyu organları tarafından dış dünyadaki olayların, olguların ve durumların beyine ulaşırken algılamada farklılıklar ile zekanın ortaya çıktığını ve zekanın kalıtımsal olduğunu savunmuştur (Walsh \& Betz, 1990). Galton ile başlayan bilimsel çalışmalar, yirminci yüzyılda Alfred Binet ve öğrencisi Theodore Simon'ın ilk zeka ölçeğini geliştirmeleri ile devam etmiştir. Bu dönemde zeka faktörü IQ kavramı kullanılarak tanımlanırken, ikinci dünya savaşından itibaren doğru zekanın sadece mantıksal ve matematiksel olmadığı, zeka testlerine ek olarak yeteneklerinde değerlendirilmesi gerektiği fark edilmiştir (Koman, 2001).

Türkiye tarafindan da imzalanan Birleşmiş Milletler Çocuk Hakları Sözleşmesine göre dünyaya gelen her çocuğun yeteneği ne olursa olsun kendi kapasitesini geliştirmek için eğitim alma ve kendini 
geliştirme hakkına sahiptir (Levent, 2014). Milli Eğitim Bakanlığı bu bağlamda kendi çatısı altında 1995 yılında ilköğretim ve ortaöğretim kurumlarına devam eden üstünlüğü kanıtlanmış olan öğrencilerin, normal eğitimlerini aksatmayacak şekilde bireysel yeteneklerini ve kapasitelerini geliştirmeleri hedeflenerek Bilim ve Sanat Merkezleri (BİLSEM) açılmıştır (Bakioğlu \& Levent, 2013). Devam eden süreçte I. Türkiye Üstün Yetenekli Çocuklar Kongresi 2004 yılında İstanbul'da yapılmıştır. bunlar;

Üstün yetenekli öğrencilerin eğitim uygulamaları genel olarak üç başlık altında toplanmaktadır

1- Hızlandırma; Üstün yetenekli bireylerin, eğitim hayatları boyunca izlenmesi gereken eğitim programını tahmini bitirilmesi gereken süreden farklı zamanda tamamlaması şeklindedir (Cutts \& Moseley, 2001). Üstün yetenekli bireylerin eğitim hayatlarında kalıcı öğrenmelerini ve sınıfta sıkılma eğilimlerini engellemek adına etkili bir stratejidir (Sak, 2011).

2- Gruplama; Üstün yetenekli bireylerin alan ile ilgili özel yetiştirilmiş öğretmenler yardımıyla, benzer üstün yetenek yada potasniyel sergileyen bireylerin tam zamanlı veya yarı zamanlı olarak eğitim görmesidir (Roedell, Jackson, \& Robinson, 1985).

3- Zenginleştirme; Üstün yetenekli bireylerin, müfredatı çeşitlendirme ve konularda üst müfredatlar yardımıyla derinleştirme sağlayarak; bilinen, gereksiz ya da yetenek düzeyinin altındaki bilgilerin çıkarılması ile sıkılma veya bunalma olmaması adına seçenek olarak kullanılan bir uygulama biçimidir (Cutts \& Moseley, 2001).

Üstün yetenekli öğrencilerin eğitimleri üç farklı yöntemden belirli yararlar sağlamak amacıyla eğitim süreci içerisinde kullanılabilmektedir.

Ülkemizde nüfusun $\% 2$ sinin üstün yetenekli olduğu bilinmekte ve 21 . Yüzyıl insan becerileri düşünüldügünde, teknolojinin insan hayatına girdiği, bireylerin teknolojinin getirisi olan ürün ve hizmetler hakkında da bilgi sahibi olması beklenilmektedir. Hem teknolojik gelişimler ve eğitim literatürlerinin takip edilmesi hem de öğrencilerin problem çözme, farklı düşünme gibi becerilerinin gelişmesi için oyun tasarımı ve kodlama eğitimleri öğrenimlere dahil edilebilir. Çoğu ülkelerin oyun tasarımı ve kodlama eğitimlerinin sağladığı katkıların farkına vararak eğitim ve öğretim müfredatlarına almış oldukları görülmektedir.

Günümüzün ihtiyaçları doğrultusunda hareket edebilmek için kodlama eğitiminin bir ihtiyaçtan daha çok bir zorunluluk olmaya başladığı görülmektedir (Sayın \& Seferoğlu, 2016). Eğitim gündeminin gerisinde kalmak istemeyen gelişmiş ve gelişmekte olan ülkeler oyun tasarım ve kodlama eğitimlerini eğitim programlarına dahil etmektedir. Millî Eğitim Bakanlığı (2018) yayımladığı 2023 Eğitim Vizyonunda, ilkokul kademesinden itibaren tüm öğretim kademelerinde, çocukların sahip oldukları yeteneklerini desteklemek amacıyla okullarda "Tasarım-Beceri Atölyeleri" kurulacağı açıklanmıştır. Kurulan atölyelerde problem çözüme, eleştirel düşünebilme, gruo çalışmalar, üretken faaliyetler ve çoklu okuryazarlık becerilerinin kazandırılma çalışmaları yapılacağı belirtilmiştir. Becerilen içeriğine bakıldığında öğrencilerin bilişimle üretim becerileri kazanmalarına yönelik, kodlama ve 3 boyutlu tasarım etkinlikleri yapılacağı vurgulanmıştır. Mevcut Eğitim programları il ve merkezlere göre değişmekle birlikte oyun tasarımı ve kodlama eğitimi çoğu kurumda ders olarak sunulmaktadır. Üstün yetenekli eğitiminde de oyun tasarımı ve kodlama temel derslerden biridir. Bilim ve Sanat Merkezilerinin (BİLSEM) yanında üstün yetenekliler için özel eğitim merkezleri, çocuk üniversiteleri, hafta sonu ve yaz okullarının üstün yetenekli bireyler için oyun tasarımı ve kodlama eğitim programları bulunmaktadır (Levent, 2011). Yapılan çalışmalar incelendiğinde üstün ve özel yetenekli öğrencilerin bilgisayar ve bilgisayar dersiyle ilişkili konulara yönelik yüksek düzeyde olumlu tutum ve bu olumlu tutumlarının yanı sıra ileri düzey bilgi ve beceri sergiledikleri görülmüștür (Keskin, 2006). Bilim ve Sanat Merkezleri (BİLSEM) başta olmak üzere üstün yetenekli öğrenciler için eğitim kodlama eğitim müfredatları zenginleştirme temel alınarak zengin içerikli programlar sunulmaktadır. 
Bilgisayar alan kazanımlarının yanında analitik düşünme, yaratıcılık ve problem çözme becerileri kazandıran oyun tasarımı ve kodlama eğitimi okul öncesi eğitiminden itibaren başlayabilmekte ve yaş sınırı olmadan devam edebilmektedir (Baz, 2018). Yaş gruplarına göre sadece kod yazmak veya sürükle bırak ile kod blokları oluşturma gibi farklı kullanım türleri olan programlar mevcuttur. Yaş grupları küçük olan gruplarda genellikle daha az hata oranı olan sürükle bırak özelliği veya açılır pencereler ile gelen seçeneklerin seçilmesi ile görsel programlama temelli kodlama yapılabilen programlar tercih edilmektedir (Grover \& Pea, 2013). Görsel programlama ve blok temelli programlama mantığı olan programlar; Kodu Game Lab, Scratch, Alice, App Inventor örnek verilebilir. $\mathrm{Bu}$ programlar, öğrencilerin karmaşık ve ham kod yazma programlama dillerinden farklı olarak karmaşık öğrenmelere gerek kalmadan, oyun tasarımı ve kodlama yapmalarını sağlamaktadır (Resnick, ve diğerleri, 2009).

Scratch: 2007 yılında "hayalinizi kodlayın" sloganı ile MIT Medya Lab'inda yer alan Lifelong Kindergarten adlı bir grup projesi olan scratch ücretsiz iki boyutlu kodlama eğitim programıdır. Görsel programlama programı olan scratchın Türkçe dil desteği mevcuttur. 8 ile16 yaş grubu öğrenciler için tasarlanan scratch ile etkileşimli hikâyeler, oyunlar, animasyonlar tasarım ve kodlama yapılabilmektedir (Resnick, ve diğerleri, 2009; Scratch, 2018)

Kodu game Lab: 2009 yılında Microsoft firması tarafından ücretsiz olarak yayımlanan üç boyutlu eğitim programıdır (Kelly, 2013). Görsel programlama programı olan kodu game labın türkçe dil desteği mevcuttur. Kodu Game Lab ile oyun tasarımı ve kodlama öğrenmenin yanı sıra öğrencilerin yaratıcılığını geliştirme, problem çözme ve öyküleme becerilerini geliştirebilmektedir (Coy, 2013; Fokides, 2018).

Üstün yetenekli çocukların; \%99,3'ünün mükemmel bir hafizaya sahip olduğu, \%99,3'ü mantığını çok iyi kullandığı ve \%97,9'u çok meraklı olduğu bilinmektedir (Rogers, 2002). 21. Yüzyıl becerileri, öğrencilerden beklenen yetenekler düşünüldüğünde üstün yetenekli öğrencilerin hedeflenen öğrenmeleri gerçekleştirmeleri daha ulaşılabilir görülmekte ve üstün yetenekli öğrenciler için tüm dünyada büyük bir eğitim hareketi olan oyun tasarımı ve kodlama eğitimi bir gereklilik olduğu sonucuna ulaşılabilir. Literatür araştırıldığında oyun tasarımı ve kodlama eğitimi ile ilgili birçok çalışmanın olduğu görülmektedir. Bu çalışmaların ortak özelliği öğrencilerin kişisel özellikleri, beceri seviyelerine bakılmadan yapılan araştırmalar veya sadece program karşılaştırmaları ile sınırlı oldukları görülmektedir. Fakat eğitimin bir gerçeği olan üstün yetenekli öğrencilerin eğitiminde bilgisayar bilimleri ile yapılmış mevcut çalışmaların azlığı göze çarpmaktadır (Keskin, 2006). Bu çalışma ile üstün yetenekli öğrencilerin oyun tasarımı ve kodlama eğitimi dersleri ile ilgili görüşleri öğrenilmesi amaçlanmaktadır.

\section{Problem Durumu}

Oyun tasarımı ve kodlama eğitim müfredat programları incelendiğinde en çok kullanılan iki program; Scratch ve Kodu Game Lab programlarıdır. Görsel programlama ve blok temelli programlama mantığının olması küçük yaştaki öğrenciler için uygun görülmektedir (Coy, 2013; Scratch, 2018). Teknolojiye çok meraklı olan üstün yetenekli öğrencilerin oyun tasarımı ve kodlama eğitimi için en çok kullanılan iki program hakkında görüşleri bulunmaya çalışılmaktadır. Bu genel amaç, çerçevesinde araştırmanın alt amaçları:

Üstün yetenekli öğrencilerin;

- Scratch programı hakkında görüşleri nelerdir?

- $\quad$ Kodu game lab programı hakkında görüşleri nelerdir?

\section{Yöntem}

Üstün yetenekli öğrencilerin oyun tasarımı ve kodlama eğitim programları scratch ve kodu game lab ile alakalı görüşlerinin belirlenmesi için nitel araştırma desenlerinden durum çalışması deseni 
kullanılmış ve araştırma yarı yapılandırılmış görüşme tekniği ile gerçekleştirilmiştir. Araştırmada veri toplama yöntemi olan görüşme; hedef kitleden seçilen kişiye, araştırma konusuyla alakalı soruların yönetilmesi ile kişinin öznel duygu ve düşüncelerini belirlenen çerçeve içerisinde öğrenmek ve tanımlamaktır (Kvale, 1996). Sosyal bilimler araştırmalarında olaylar ve olgular karmaşık ve çok boyutlu olduklarından bir problem durumunun tüm bakış açılarının anlaşılabilmesi için katılımcıların derinlemesine araştırılması, fikirlerinin tüm yönleriyle aktarılabilmesi için görüşme yönteminin kullanılmasının araştırmayı güçlü ve etkili hale getireceğinden araştırma için yararlı olduğu belirtilmektedir (Patton, 2001; Creswell, 2003). Görüşme tekniklerinden seçilen, yarı yapılandırılmış görüsşme tekniği sahip olduğu esneklik nedeni ile eğitim bilim araştırmalarında daha uygun bir teknik olarak düşünüldüğü için araştırmada kullanımı uygun görülmüştür (Ekiz, 2003).

\section{Katılımcilar:}

Araştırma katılımcıları; Türkiye, Bursa ilinde bulunan, 10 yaşında üstün yetenekli oldukları belirli testlerle raporlaştırılmış 20 öğrencidir. Raporlaştırmada kullanılan testler; Stanford-Binet Zeka testi ve WISC-R testi kullanılmıştır. Öğrenciler hafta sonu eğitim kursunda haftada bir saat olarak 20 hafta, 10'ar saatlik Scratch ve Kodu Game Lab program eğitimlerini almışlardır. Eğitimin gerçekleştiği ortamda tüm öğrencilerin kendi bilgisayarları bulunmakta ve sınıf mevcudu 8 ile 10 kişi arasında eğitimler gerçekleşmiştir. Ders süreleri ve eğitim içerikleri oluşturulurken bir üstün yetenek eğitmeni, bir psikolog ve bir bilgisayar eğitmeni tarafindan belirlenmiştir. Eğitim içerikleri zenginleştirme temel alınarak, belirlenen programın yaş grubuna göre bir veya iki üst kademe için hazırlanan ders içerikleri incelenerek scratch ve kodu game lab programları için ayrı ayrı alan kazanımları ve üstün yeteneklilerin üst düzey ulaşılması istenen kazanım hedefleri belirlenerek oluşturulmuştur.

\section{Veri Toplama Aracı ve Verilerin Toplanması:}

Araştırma nitel araştırma yöntemleri kullanılarak yapılırken toplanan veriler yarı yapılandırılmış görüşme formu ile elde edilmektedir. Yarı yapılandırılmış görüşme formunda ilk önce soruları hazırlanır fakat Görüşmenin akışına göre hazırlanan sorulardan farklı veya konunun alt basamaklarıyla alakalı sorular görüşmenin akışına göre dahil edilebilir. Bunun yanında görüşme esnasında katılımcı soruların yanıtlarını başka soruların içerisinde yanıtlamış ise araştırmacı bu soruları sormama esnekliğine de sahiptir. Yarı yapılandırılmış görüşme tekniğinin bu özellikleri ile sosyal bilim araştırmalarında sıkça kullanılmaktadır (Ekiz, 2003). Nicel araştırmalarda geçerliği ve güvenirliği ölçmek sistematiktir. Nitel araştırmalarda ise bu durum biraz daha karışık olmakla birlikte yansız gözlemler, birden fazla araştırmacının araştırmaya dahil edilmesi, uzman yardımı ile sağlanılmaktadır (Kirk \& Miller, 1986; Patton, 2001). Araştırmada geçerlik ve güvenirlik sağlanabilmesi için araştırmacının; veri toplanması, analiz edilmesi ve yorumlanmasında tutarlı olmalı ve araştırmacının sonuçlara nasıl ulaştığını ortaya koyması beklenir (Yıldırım \& Şimşek, 2018).

Yarı yapılandırılmış görüşmeler için görüşme formunun hazırlanma sürecinde bir bilgisayar öğretmeni ve bir üstün yetenek eğitim uzmanı ortak çalışmışlardır. Görüşme sorularının içeriği oluşturulurken; ulusal ve uluslararası alanyazın incelenmiştir. Oluşturulan görüşme formu Uludağ Üniversitesi Bilgisayar ve Öğretim Teknolojileri Bölümü öğretim üyerlerine görüşmeler yapılmadan danışılmıştır. 5 olan soru sayısı 2' ye ndirilerek soruların cümle yapılarında değişiklikler yapılmıştır. Bunlar;

- Scratch programı hakkında olumlu ve olumsuz olarak düşüncelerini belirtebilir misin?

-Kodu game lab programı hakkında olumlu ve olumsuz olarak düşüncelerini belirtebilir misin?

Nitel araştırmalarda görüşmelerin araştırma için yapılan çalışmaların son basamağında kullanılması çalışma açısından en uygun zaman dilimidir (Fraenkel \& Wallen, 2005). Bu sebeple görüşmeler eğitimlerin bitmesini kapsayan son haftada gerçekleşmiştir. Üstün yetenekli öğrencilerin ve velilerinin izni ve gönüllü katılımıyla gerçekleşmiş ve tek tek öğrenciler ile yapılan her görüşme 
ortalama 8 ile 10 dakika sürmüştür. Tüm görüşmeler ses kaydına alınarak verilerin kaybı önlenmeye çalışılmıştır.

\section{Verilerin Analizi:}

Yarı yapılandırılmış görüşmeler tamamlandıktan sonra elde edilen ses kayıtlarının bilgisayar ortamına aktarımı yapılmıştır. Bilgisayara aktarılan görüşme notları, sorulara göre bir sınıflama yapılarak toplanan veriler içerik analizi- tümevarım analiz temel alınarak işleme başlanmıştır. İçerik analizi toplanan verileri açıklamak için kavramlar oluşturarak fark edilemeyen, araştırmanın derinlerinde bulunan kavram ve temaları bulmaktır (Yıldırım \& Șimșek, 2018). İçerik analizi tümevarım yönteminde veriler ilk önce kodlanır daha sonra verileri yansıtan temalar bulunur, veriler kodlara ve temalara göre düzenlenir ve tanımlanırlar. Son aşamada elde edilen bulgular yorumlanır (Yıldırım \& Şimşek, 2018). Tümevarım analizi temel alınarak verilerin analizi için iki farklı araştırmacı tarafından veriler incelenerek anlamlı bölümlere ayrılmış ve kodlanmıştır. Bulunan kodların ve araştırmanın güvenirliğini ortaya koymak üzere Cohen Kappa katsayısından yararlanılmıştır. Kappa testi iki veya daha fazla araştırmacı verileri arasındaki uyumun güvenirliğini ölçen parametrik olmayan bir istatistik yöntemidir (Cohen, 1960). İki araştırmacının kodlamaları matris tablosu hesaplanmış ve \%87 ile veriler arasında çok iyi derecede uyum bulunmuştur (Landis \& Koch, 1977). Kodlanan veriler bir araya getirilerek kategorize edilmiş ve ilişkili temalar bulunmuştur. Elde edilen temaların güvenirliği için alan bilgisine ve nitel araştırma bilgisine sahip bir öğretim üyesi ve bir uzmanın görüşüne başvurularak, çalışmada veri üçgenlemesi yöntemi kullanılmıştır; bir ya da daha fazla veri kaynağının sonuçlarının karşılaştırılması yapılarak ortaya çıkan verilerin, kaynakların birinin eksik yönü diğer yöntemin güçlü yönüyle telafi edilebilmesi amaçlanmaktadır (Patton, 2001). Son olarak tanımlanan bulgular yorumlanmıştır.

\section{Bulgular} bunlar;

İki görüşme sorusundan elde edilen veriler analiz edilip temalara ayrıldığında 4 tema oluşmuştur

Üstün yetenekli öğrencilerin: Scratch programındaki olumlu görüşleri, scratch programındaki olumsuz görüşleri, kodu game lab programındaki olumlu görüşleri , kodu game lab programındaki olumsuz görüşlerine ilişkin görüşleri şeklindedir.

\section{Üstün yetenekli öğrencilerin scratch programı hakkında olumlu görüşleri:}

Üstün yetenekli öğrencilerin scratch programı hakkında olumlu görüşlerine ilişkin bulgular Tablo 1'de verilmiştir.

Tablo 1: Üstün yetenekli öğrencilerin scratch programı hakkında olumlu görüşleri

\begin{tabular}{lcc}
\hline Scratch programındaki olumlu görüşleri & Frekans(N=20) & $\%$ \\
\hline Kendi içerisinde bulunan nesne ve temalar & 10 & 50 \\
Kolay kullanım & 5 & 25 \\
Türkçe dil desteği & 4 & 20 \\
Diğer görüşler & 1 & 5 \\
\hline
\end{tabular}

Tablo 1.'e bakıldığında scratch programı hakkında öğrencilerin olumlu görüşleri ile ilgili analizlerin \%50'si $(n=10)$ program içerisinde yer alan nesneler ve temaların hoşlarına gittiği belirtmişlerdir.

Akın, "Programda her şey düşünülmüş, mesela uzayla ilgili oyun yapacaksın hem kuklalar hem de arka plan programın içerisinde var." Elif, "Benim en hoşuma giden şey nesnelerin çokluğu ve kllık değiştir komutu ile değiş̧me özellikleri... ”Şeklinde ifade etmişlerdir.

Öğrencilerin $\% 25{ }^{\mathrm{i}}(\mathrm{n}=5)$ kolay bir kullanımı olduğunu belirtmişlerdir. Merve, "Siz ilk gösterdiğinizde ne kadar kolay bir program demiştim, kullanmak çok kolay..." şeklinde ifade etmiştir. 
Öğrencilerin \% 20'si (n=4) Türkçe dil desteğinin programda büyük kolaylıklar sağladığını ve $\% 5$ 'i $(n=1)$ hem bilgisayara yüklenmesinin hem de internet üzerinden programı ulaşılmasının güzel bir özellik olduğunu belirtmişlerdir. Taha, "Biz okulda da bu programı kullaniyoruz, internet sayesinde okul sınıf arkadaşlarıma yaptığım her şeyi gösterebiliyorum.” şeklinde ifade etmiştir.

\section{Üstün yetenekli öğrencilerin scratch programı hakkında olumsuz görüşleri:}

Üstün yetenekli öğrencilerin scratch programı hakkında olumsuz görüşlerine ilişkin bulgular Tablo 2'de verilmiştir.

Tablo 2: Üstün yetenekli öğrencilerin scratch programı hakkında olumsuz görüşleri

\begin{tabular}{lcc}
\hline Scratch programındaki olumsuz görüşleri & Frekans(N=20) & $\%$ \\
\hline Üç boyut eksikliği & 13 & 65 \\
Dışarıdan alınan nesnelerin uyumsuzluğu & 3 & 15 \\
Kod bloklarının karışıklığı & 3 & 15 \\
Diğer görüşler & 1 & 5 \\
\hline
\end{tabular}

Tablo 2.'ye bakıldı ğında scratch programı hakkında öğrencilerin olumsuz görüşleri ile ilgili analizlerin öğrencilerin \%65'i $(n=13)$ programın üç boyutlu görüntü sağlamamasının çok büyük bir eksik olduğunu belirtmişlerdir. Berçin, "Keşke kodu game lab programındaki gibi üç boyutlu olsaydl." Ege, "Artı tüm oyunlar ellini ekrana götürdügünde oyunun içine girebilecekmişsin gibi ama scratch sanki eski oyunlar gibi duruyor." Şeklinde ifade etmiş̧lerdir.

Öğrencilerin \%15'i $(n=3)$ dışarıdan tasarım içerisine aktarılan resimlerin program içerisinde bulunan nesneler ile uyumsuz durduğunu, \% 15'si $(\mathrm{n}=3)$ kod bloklarının karışık olduğunu ifade etmişlerdir. Armağan "Kodları ayıran menüler bazen çok karışık ve içerisindeki kodlarla uyumsuz oluyor. Birinin bunları düzenlemesi gerek." Şeklinde ifade etmiştir.

Öğrencilerin \%5'i $(\mathrm{n}=1)$ nesne hareketlerinin yetersiz olduğunu belirtmişlerdir. Tark, "Bir karakteri hem yukarı hem aşağı hem sağa hem sola hareket ettirmek çok zor. Herkes bilir oyunlarda en önemli olan şey harekettir. ” şeklinde ifade etmiştir.

\section{Üstün yetenekli öğrencilerin Kodu game lab programı hakkında olumlu görüşleri:}

Üstün yetenekli öğrencilerin kodu game lab programı hakkında olumlu görüşlerine ilişkin bulgular Tablo 3'de verilmiştir.

Tablo 3: Üstün yetenekli öğrencilerin kodu game lab programı hakkında olumlu görüşleri

\begin{tabular}{lcc}
\hline Kodu game lab olumlu görüşleri & Frekans(N=20) & $\%$ \\
\hline Üç boyut desteği & 14 & 70 \\
Kodlama kolaylığı & 3 & 15 \\
Ana menü & 2 & 10 \\
Türkçe dil desteği & 1 & 5 \\
\hline
\end{tabular}

Tablo 3.'e bakıldığında kodu game lab programı hakkında öğrencilerin olumlu görüşleri ile ilgili analizlerin \%70'i (n=14) program üç boyutlu olmasının en güzel özelliği olduğunu belirtmişlerdir. Berçin, "Programa girdiğinizde sizi kendine bağllyor görüntüsüyle." Tuana, "Diyelim ki oyun tasarliyorsun, bir nesne eklediğinde her tarafinı görüp sanki elinle tutabilecek gibi hissediyorsun." Ege, "Renkler çok canlı üç boyutlu olduğundan belki de öyle." Şeklinde ifade etmişlerdir.

Öğrencilerin \%15'i (n=3) kodlamanın açılır pençeler sayesinde kolay ve daha düzenli olduğunu, Taha, "Program içerisinde hareket etmek çok kolay..." Şeklinde ifade etmiştir.

\%10’u ( $\mathrm{n}=2)$ ana menünün belirgin ve küçük resimlerinin olmasının beğendiklerini Befru "yazıları unutsam ne işe yaradıklarını resimleri hatırlıyorum, " ve \% 5'i (n=1) Türkçe dil desteğinin 
programda büyük kolaylıklar sağladığını belirtmişlerdir. Merve, "Böyle bir programın türkçe olması çok güzel. ”Şeklinde ifade etmişlerdir.

\section{Üstün yetenekli öğrencilerin Kodu game lab programı hakkında olumsuz görüşleri:}

Üstün yetenekli öğrencilerin kodu game lab programı hakkında olumsuz görüşlerine ilişkin bulgular Tablo 4'de verilmiştir.

Tablo 4: Üstün yetenekli öğrencilerin kodu game lab programı hakkında olumsuz görüşleri

\begin{tabular}{lcc}
\hline Kodu game lab olumsuz görüşleri & Frekans(N=20) & $\%$ \\
\hline Dışarıdan nesne alınamaması & 17 & 85 \\
Dünya nesne azlığı & 2 & 10 \\
Diğer görüşler & 1 & 5 \\
\hline
\end{tabular}

Tablo 4.’e bakıldığında kodu game lab programı hakkında öğrencilerin olumsuz görüşleri ile ilgili analizlerin öğrencilerin \%85'i (n=17) dışarıdan nesne alınarak program içerisine eklenememesinin çok büyük bir eksik olduğunu belirtmişlerdir. Berçin, "Bir yerden sonra sürekli aynı nesneleri, aynı robotları görmekten sikıllyorsun." Arda, "Başka oyunlarda bir sürü karakter var onları da yaptığım oyuna eklemek istiyorum ama ekle seçeneğinin olmadı̆̆ aklıma geliyor ve canım slkılıyor." Şeklinde ifade etmişlerdir.

Öğrencilerin \%10’u (n=2) dünya ile alakalı nesnelerin az olduğunu ve insan figürünün eklenmesi gerektiğini, Akın, "Mesela ev eklemek istiyorsunuz ama yok, insan zaten yok bunlar da olmall." Şeklinde ifade etmiştir.

Öğrencilerin \% 5'i (n=1) program içerisinde çok kısıtlama ve kural olduğunu, "Programda çok kural var mesela siz çok nesne eklemek istiyorsunuz olmuyor çünkü dolmuş, yada mesela ağaç hareket etsin istiyorsunuz olmuyor. " Şeklinde ifade etmiştir.

\section{Tartışma, Sonuç ve Öneriler}

$\mathrm{Bu}$ araştırma ile üstün yetenekli öğrencilerin oyun tasarımı ve kodlama eğitimi derslerinde en çok kullanımı tercih edilen iki program hakkında görüşlerini öğrenmek amaçlanmıştır. Öğrencilerin scratch programı ile alakalı nesnelerin çokluğu, renk kaliteleri ve kodlama bölümünü çok beğendikleri belirlenmiştir. Görüntü kalitesi ve programın dijital boyutunun program hakkında olumlu düşünceleri azalttığ görülmektedir çünkü dijital oyunlarda sıkça kullanılan 3 boyutlu görüntü kalitesini kendi tasarladıkları oyunlarda da bekledikleri görülmüştür. Bununla alakalı "Artık insanlar sanal gerçeklik gözlükleri ile oyunların içine girebiliyorken scratchta yapılanlar biraz basit, eski duruyor ve benimde eski bir oyun yapma isteğim yok." Şeklinde öğrenci yorumları belirlenmiştir. Öğrenciler tasarladıkları oyunun içine ne kadar dahil olabilirlerse problem çözme becerilerin gelişmesine katk1 sağlanacağ düşünülmektedir (Jonassen, 2000).

Öğrencilerin tercih ettikleri bir diğer durum ise oyun tasarımlarının içerisine dışarıdan nesne dahil edilmesidir. Scratch ile bu mümkün iken Kodu game lab programında böyle bir özellik bulunmamaktadır. Konu ile alakalı bir öğrenci "Kodu game lab’ görselliği ve kodlama ekranı için tercih ediyorum ama scratch programındaki gibi istediğimiz resim ve arka plan ekleme özelliği olmamaya devam ederse aynı nesneleri kullanmaktan sıkllip birakabilirim. ”ş̧eklinde belirtmiştir.

Scracth ve kodu game lab programlarının kodlama bölümünde blok temelli kodlama kullanılmaktadır. Fakat kodu game lab ek özellik olarak kodlama bloklarına resim özelliği ekleyerek öğrencilerin sadece okuma yazma ile değil aynı zamanda görsel yardım ile kodlama yapmalarına yardım etmeyi amaçladığı görülmektedir. Bir öğrenci bu konu ile alakalı "Bazen evde kodu ile program yaparken okuma yazma bilmeyen kardeşim bana eşlik edebiliyor." şeklinde belirtmiştir. Programlarda türkçe dil desteğinin olması öğrenciler için olumlu bulunmuştur, kodu ile alakalı bir öğrenci; 
"Kullandığımız programlar türkçe olduğu için sanki onunla arkadaşmışı gibi geliyor. Türkçe olmayan programlarda ne istediklerini bilmiyorum ve bu beni geriyor. " Şeklinde belirtmiştir.

Üstün yetenekli öğrencilerin öğrenmelerini hızlı gerçekleştirmeleri genel özelliklerinden biridir (Uzun, 2006). Bir öğrenci bu durumu "Her hafta derse girdiğimde nesnelere bakarım programlara yeni nesne eklediler mi diye? Ama büyük bir değişiklik olmayınca üzülüyorum." Şeklinde belirtmiştir. Bu sebeple programların sürekli güncellenmeleri ve yeni özelliklerin eklenmesi gerektiğini görülmektedir.

Alanyazında benzer çalışmalar incelendiğinde öğrencilerin genel olarak scratch programını beğendiklerini fakat kodlama bölümünde döngü, olaylar ve koşulların gibi soyut programlama yapılarından somuta geçirildiğini belirlenmiştir (Gezgin, Özcan, Ergün, \& Köse, 2017; Sırakaya, 2018). Üstün yetenekliler ise kodlama bölümünün hala karmaşık bir yapıya sahip olduğunu belirtmişlerdir.

Gerçekleştirilen araştırma alanı olan oyun tasarımı ve kodlama eğitimiyle ilgili olarak yapılan akademik çalışmaların az olduğuna işaret etmektedir. Üstün yeteneklilerin oyun tasarımı ve kodlama eğitimi ile ilgili akademik çalışmalar ise çok az olduğu belirlenmiştir. Gelecek çalışmalar için katılımcı sayısı arttırılarak, araştırmaya daha fazla oyun tasarımı ve kodlama eğitim programları eklenerek çalışmalar genişletilebilir. Araştırma yöntemleri nitel ile sınırla kalmayıp nicel ve karma yöntem ile araştırmalar yapılabilir.

Çalışmanın sadece nitel verilere dayanması ve içerik analizi ile sınırlandırılmış olması çalışmanın sınırlılıklarından biridir. Oyun tasarımı ve kodlama programlarının çeşitliliği göz önüne alındığında iki program ile çalışılması sınırlılıktır ve daha fazla programın eğitim içeriğine alınarak değerlendirilmesi yapılabilir.

\section{Kaynakça}

Bakioğlu, A., \& Levent, F. (2013). Üstün Yeteneklilerin Eğitiminde Türkiye İçin Öneriler. Üstün Yetenekliler Eğitimi Araştırmaları Dergisi, 1(1), 31-44.

Baz, F. C. (2018). Çocuklar İçin Kodlama Yazılımları Üzerine Karşılaştırmalı Bir İnceleme. Curr Res Educ, 4(1), 36-47.

Cohen, J. (1960). A coefficient of agreement for nominal scales. Educational and Psychological Measurement, 20(1), 37-46.

Coy, S. (2013). Kodu game lab, a few lessons learned. XRDS, 19(4), 44-47.

Creswell, J. W. (2003). Research design: Qualitative, quantitative, and mixed methods approaches (2nd ed.). Thousand Oaks,: CA: Sage.

Cutts, N. E., \& Moseley, N. (2001). Üstün Zekalı ve Yetenekli Çocukların Eğitimi. (Çeviren: İsmail Ersevim). İstanbul: ÖZGÜR YAYINLARI.

Ekiz, D. (2003). Eğitimde Araştırma Yöntem ve Metotlarına Giriş. Ankara: Anı Yayıncılık.

Fraenkel, J. R., \& Wallen, N. E. (2005). How to design and evaluate research in education (6th ed.). New York: McGraw-Hill: Higher Education.

Grover, S., \& Pea, R. (2013). Computational thinking in K-12 a review of the state of the field. Educational Researcher, 42(1), 38-43.

Jonassen, D. H. (2000). Toward a design theory of problem solving. Educational Technology Research and Development, 48(4), 63-85.

Kelly, J. F. (2013). Kodu for Kids. Quebec: Pearson Education. 
Keskin, S. (2006). Üstün Ve Özel Yetenekli Çocuklar Ve Bilgisayara Ve Bilgisayar Dersine Yönelik Tutumlarl (Yüksek Lisans Tezi). http://cocukuniversitesi.aydin.edu.tr/tez/bilgisayar.pdf adresinden alınd 1

Kirk, J., \& Miller, M. L. (1986). Reliability and Validity in Qualitative Research. Beverly Hills: CA: SAGE .

Koman, E. (2001). Zeka ne değildir? Çoluk Çocuk Dergisi, 26(3), 37-38.

Kvale, S. (1996). InterViews: An Introduction to Qualitative Research Interviewing. Thousand oaks: SAGE Publications.

Landis, J. R., \& Koch, G. G. (1977). The measurement of observer agreement for categorical data. International Biometric Society, 33(1), 159-174.

Levent, F. (2011). Üstün Yetenekli Çocukların Hakları. İstanbul: Çocuk Vakfı Yayınları.

Levent, F. (2014). Üstün Yetenekli Çocukları Anlamak. Ankara: Nobel Yayıncılık.

Milli Eğitim Bakanlığı. (2018). Güçlü Yarınlar için 2023 Eğitim Vizyonu. Ankara: MEB.

Moore, A. D. (1992). Gifted and Talented Children and Youth - Exceptionalities in Children and Youth . (Ed. L.M. Bullock ) .USA: Allyn and Bacon Inc.

Patton, M. Q. (2001). Nitel araştırma ve değerlendirme yöntemleri (M. Bütün, S. B. Demir Çev. Eds.) . Ankara: Pegem Akademi.

Renzulli, J. S. (1999). What is This Thing Called Giftedness, and How Do We Develop It? A TwentyFive Year Perspective. Journal for the Education of the Gifted, 23(1), 3-54.

Resnick, M., Maloney, J., Monroy-Hernández, A., Rusk, N., Eastmond, E., Brennan, K., . . Kafai, Y. (2009). Scratch: Programming For All. Communications of the ACM, 50(11), 60-67.

Roedell, W. C., Jackson, N. E., \& Robinson, H. B. (1985). Gifted Young Children. New York: Teachers College Press.

Rogers, K. B. (2002). Re-Forming Gifted Education: How Parents and Teachers Can Match the Program to the Child. Arizona: Great Potential Press.

Sak, U. (2011). Üstün Zekalılar Özellikleri, Tanılanmaları, Eğitimleri. Ankara: Maya Yayıncılık.

Sayın, Z., \& Seferoğlu, S. S. (2016). Yeni Bir 21. Yüzyıl Becerisi Olarak Kodlama Eğitimi ve Kodlamanın Eğitim Politikalarına Etkisi. Akademik Bilişim Konferansı, Aydın: XVIII.

Scratch. (2018). Scratch About. Scratch: https://scratch.mit.edu/about adresinden alındı

Türk Zeka Vakfi. (2013). Zeka testlerinin tarihçesi. Ankara: Türkiye Zeka Vakfi.

Uzun, M. (2006). Üstün veya Özel Yeteneklilik Nedir? I. Türkiye Üstün Yetenekli Çocuklar Kongresi El Kitabı. İstanbul: Çocuk Vakfı Yayınları.

Walsh, W. B., \& Betz, N. E. (1990). Tests and Assessment. (2nd ed.). Englewood Cliffs: NJ: Prentice Hall.

Yıldırım, A., \& Şimşek, H. (2018). Sosyal bilimlerde nitel araştırma yöntemleri. Ankara: Seçkin Yayınc1lı. 